\title{
Presentación / Presentation
}

La perspectiva transnacional que se está desarrollando en la producción historiográfica encuentra en los estudios sobre el catolicismo un espacio privilegiado de análisis, y dentro de él las congregaciones religiosas constituyen un ámbito propicio para observar conexiones, circulaciones e intercambios.

Los trabajos reunidos en este dossier ofrecen un aporte para analizar la movilidad de mujeres y varones europeos que llegan a América dispuestos a impregnar de sus tradiciones culturales el nuevo espacio; con ellos viajan ideas, experiencias y devociones en un gran equipaje que, a la vez, se nutrirá de color local.

Las congregaciones de origen francés fueron las que enviaron más misioneros a los distintos continentes y, en América Latina, la influencia del catolicismo de cultura francesa marcó un estilo en la educación y en las prácticas devocionales, así como también en la arquitectura. Tres de los artículos que componen este dossier dan cuenta de la transmisión del catolicismo francés en América Latina.

En primer lugar, el artículo titulado «Para una historia transnacional de las congregaciones religiosas femeninas (siglos XIX y XX)", de Bruno Dumons, nos brinda un completo panorama de la producción historiográfica referida a las mujeres religiosas, enfatizando la visibilidad que obtuvieron las mismas a partir de los avances en la producción de historia de mujeres y estudios de género. Este giro en la investigación histórica renovó ampliamente la historia de las congregaciones femeninas y puso de relieve el importante rol que estas desempeñaron en América, África, el Sudeste Asiático, China y Japón en los ámbitos de la salud, la educación, la filantropía y la ayuda humanitaria. Dumons revela los avances de la historiografía francesa y alemana para analizar la circulación de conocimientos y los intercambios entre religiosas europeas y religiosas nativas de América y África, y para estudiar los inestimables esfuerzos de modernización de los espacios educativos destinados a mujeres. Asimismo, este autor se refiere a la fundación de conventos de vida contemplativa, tomando como caso de estudio la expansión del Carmelo francés y la difusión de la vida y camino espiritual de Teresita de Lisieux en América, ejemplo de esta «transnacionalización de un culto en femenino". También analiza otras devociones, como la adoración eucarística, el Sagrado Corazón y devociones marianas europeas que invadieron todo el continente americano. En su estudio, Dumons señala el punto de inflexión de la década de 1960 con los cambios operados dentro del movimiento feminista y su impacto en las congregaciones religiosas, a los que se suman los documentos del Concilio Vaticano II, que provocaron cambios profundos en la autocomprensión de las mujeres religiosas, tanto en el ámbito de las propias congregaciones como en relación con el lugar que ocupan en la institución eclesiástica en general.

El segundo artículo de este dossier, «Las mujeres religiosas y las guerras civiles: Los inicios de la ayuda humanitaria en Colombia» de Beatriz Castro Carvajal, relata la historia de las primeras religiosas de vida apostólica que desem- 
barcaron en Colombia provenientes de Francia, en la segunda mitad del siglo XIX, las Hermanas de la Caridad Dominicas de la Presentación. Estas mujeres religiosas se desempeñaron como enfermeras en las guerras civiles colombianas y en la guerra colombo-peruana, y sus actividades en los hospitales de campaña o ambulancias quedaron registradas en un gran número de cartas y diarios que dan a conocer detalles de la situación política colombiana y de las prácticas médicas llevadas adelante por mujeres en contextos de guerra. Religiosas de esta congregación habían servido como enfermeras en la guerra franco-prusiana de 1870, por lo que ya tenían experiencia de estar en el frente de batalla. Castro asevera que este servicio sanitario y humanitario permitió fortalecer los vínculos con el Estado colombiano, ya que fueron consideradas personas confiables por parte de los distintos gobiernos; además, estas religiosas fueron quienes inauguraron la ayuda humanitaria neutral en Colombia. La circulación de saberes médicos y religiosos consolidó esta congregación francesa en este país, que en los inicios del siglo xx ya estaba constituida en su mayoría por mujeres religiosas colombianas.

Alexandrine de La Taille-Trétinville, en su estudio «Redes católicas y devociones en Chile: el legado de la educación "a la francesa" de la Sociedad del Sagrado Corazón en el cambio de siglo (1870-1920)», indaga en el modelo educativo y devocional de las religiosas del Sacré-Coeur que llegaron a Chile en 1854. Demuestra que esta congregación realizó un aporte fundamental para la modernización de la educación femenina y fomentó la cooperación de la cultura francesa en la circulación de saberes y prácticas de piedad. La Taille-Trétinville se detiene en las nuevas devociones galas y su arraigo en Chile, sobre todo en las advocaciones marianas - especialmente la de Lourdes, cuyas grutas se construyeron a lo largo de todo Chile-, y también en las lecturas edificantes que promovieron en sus centros de formación, como ejemplo de transferencia cultural francesa. La autora realiza esta investigación a partir de los escritos de tres alumnas del Sacré-Coeur de Chile: Juanita Fernández Solar (1900-1920), futura Teresa de Los Andes; Ana Luisa Larraín García Moreno (1882-1925) y Blanca Subercaseaux Errázuriz (1886-1966).

Por último, el artículo de Maria Aparecida Corrêa Custódio, «Lucha y resistencia de las mujeres negras en la carrera religiosa en Brasil: el análisis de caso de las Hermanas de la Congregación de las Hermanas Misioneras de Jesús Crucificado», focaliza la problemática del racismo en el interior de un instituto religioso a partir del testimonio de las mismas religiosas negras, pertenecientes a la Congregação das Irmãs Missionárias de Jesus Crucificado, fundada en 1928 en la ciudad de Campinas (São Paulo). A pesar de tratarse de la primera congregación religiosa que asumió una política vocacional que permitió el ingreso de mujeres negras, las mismas tuvieron que asumir solo tareas domésticas y subalternas. Recién tras el Concilio Vaticano II, sus luchas por la igualdad racial y de derechos tuvieron acogida. El proceso que vivió la Iglesia latinoamericana, reflejado en los documentos de Medellín (1968) y Puebla (1979), provocó un desplazamiento hacia la vida religiosa inserta en medios pobres, y las religiosas, en el encuentro con la población negra de los barrios marginales, crecieron en su conciencia de la negritud. A su vez, al interior de la congregación se organi- 
zaron encuentros de las hermanas negras que permitieron fortalecer los pasos de emancipación y valoración de su identidad negada.

Los trabajos reunidos aquí nos permiten viajar por Brasil, Colombia, Chile y Francia de la mano de religiosas viajeras, educadoras, enfermeras y trabajadoras sociales, y descubrir conexiones, ideas, experiencias, devociones y lecturas que viajaban junto con ellas, pero también prácticas de dominación y resistencia. Así, los estudios de las congregaciones femeninas nos abren la puerta a continuar indagando en una historia transnacional en la que las mujeres también son protagonistas de los intercambios e influencias.

Fecha de recepción: 6 de enero de 2021

Fecha de aceptación: 17 de marzo de 2021

Fecha de publicación: 30 de junio de 2021 